
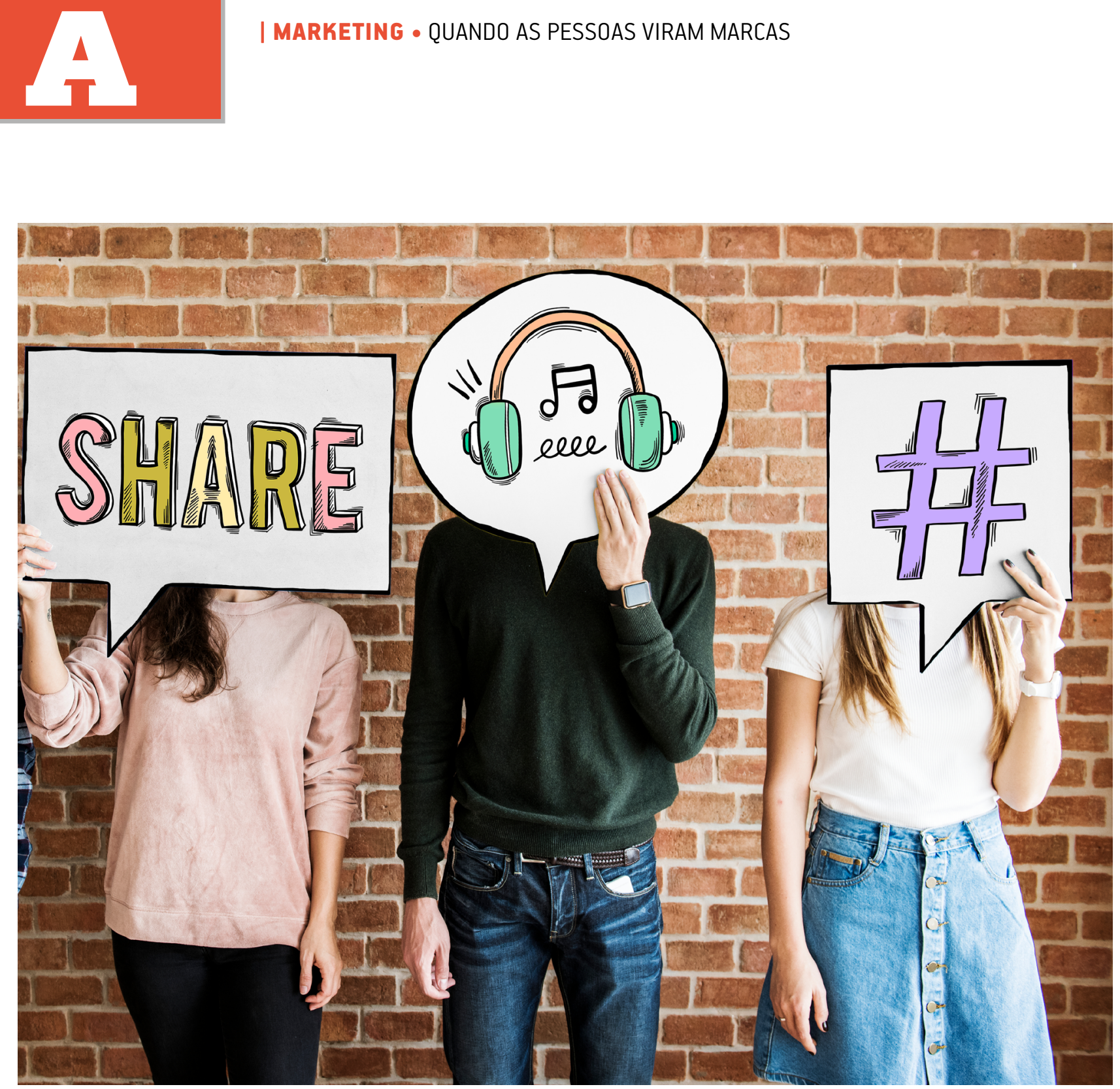

\title{
QUANDO AS PESSOAS VIRAM MARCAS
}

UMA ANÁLISE DO USO DE PERSONAS PARA ATRAIR SEGUIDORES E PROMOVER CAUSAS NAS REDES SOCIAIS. 


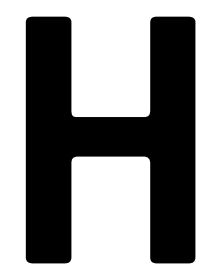

ouve uma época em que uma celebridade era construída na televisão. Jornalistas, atores e cantores ganhavam fama com a notoriedade e a presença constante nas poucas opções de mídia existentes. Desde que o padrão de consumo de mídia se transformou, com o surgimento das redes sociais, as possibilidades de construção de atenção foram, em certo grau, democratizadas. Atualmente, tanto uma jornalista com décadas de experiência como Oprah Winfrey quanto uma menina sueca de 17 anos podem ser agentes bem-sucedidos na economia da atenção que vigora nas mídias sociais.

A menina sueca em questão é Greta Thunberg, eleita personalidade do ano de 2019 pela revista Time. Seu feito: utilizar a força da rede para produzir um enorme movimento de ativismo ecológico e de pressão sobre governos nacionais. A ativista conta com 9,2 milhões de seguidores no Instagram e 2,7 milhões no Facebook, mesmo não sendo uma especialista - uma cientista, por exemplo - na área ambiental. Além de ser emissora de conteúdo, ela mesma é assunto consumido e transmitido por dezenas de milhões de outros nódulos nas redes.

Greta ilustra um fenômeno impulsionado pelas mídias sociais: o da chamada marca pessoa. Essa marca pode ser construída tanto por digital influencers de profissão - que seriam já mais de 500 mil somente no Instagram, segundo o site eMarketer - quanto por qualquer um que deseje construir uma imagem com suas mensagens nas redes para fins profissionais, como para a promoção de causas.

\section{A MARCA PESSOA}

A marca pessoa tratada aqui não funciona igual à de uma celebridade, como Oprah. A celebridade é trabalhada a partir de quem atingiu posição de extremo destaque social em sua área. A pessoa comum jamais poderia estruturar sua marca por esse ponto de partida, embora com o tempo possa chegar ao status de celebridade, caso da própria Greta.

Em seu livro Understanding Celebrity, Graeme Turner cunhou o termo "virada demótica" para se referir à crescente visibilidade das pessoas comuns. Era 2004, ano de criação do Facebook, e ainda não existiam YouTube, Instagram, Snapchat, Twitter nem Linkedln, mas Turner já captou então a tendência das práticas do faça-você-mesmo sua própria celebridade propagadas por programas como American Idol. Com a proliferação das mídias sociais, essas práticas intensificaram-se.

Em artigo publicado no Journal of Marketing Management, os pesquisadores Delphine Dion e Eric Arnould dizem que

\section{TODA PERSONA COMUNICADA PARTE DE UM OBJETIVO, QUE PODE SER MINUCIOSAMENTE PLANEJADO OU INTUITIVAMENTE CONSTRUIIDO.}

a marca pessoa deve ser entendida como uma marca persona, pois não é a pessoa quem fala, mas sim uma persona cuidadosamente comunicada. A persona pode ser definida como uma máscara que permite ao público identificar a marca. Carl Gustav Jung tratava essa máscara como uma parte da personalidade do indivíduo que ajuda a organizar sua relação com o outro. Temos na vida muitas máscaras que usamos em diferentes papéis sociais do cotidiano. Há a persona profissional e a persona materna ou paterna, a do vizinho de condomínio e a do amigo do grupo.

\section{CAMINHOS DO SELF-BRANDING}

Como essa marca pessoa é construída? Por meio do self-branding. De acordo com os acadêmicos Susie Khamis, Lawrence Ang e Raymond Welling, o self-branding é o ato de desenvolver uma imagem pública para ganhos comerciais e construção de capital cultural (e eu acrescento aqui capital social). Não é uma ideia nova. Em 1997, Tom Peters e seu artigo The Brand Called You foram capa da revista Fast Company, recomendando a todos que construíssem suas marcas profissionais para se destacarem no mercado de trabalho. O que há de novo é a maneira como esse conceito saiu do mundo dos negócios e foi parar em toda parte. Qualquer pré-adolescente que sonhe em virar estrela do YouTube segue fielmente princípios de self-branding.

A construção da marca pessoa na prática cotidiana do self-branding baseia-se em quatro pilares: o objetivo desejado, a personalidade comunicada (a persona), o conteúdo e a relação com o público.

Toda persona comunicada parte de um objetivo, que pode ser minuciosamente planejado ou intuitivamente construído. Se a intenção for se posicionar como um especialista em certa área, seja um ativista do meio ambiente, seja um planejador financeiro, as decisões de personalidade comunicada, conteúdo produzido e relacionamento com os públicos serão uma decorrência desse objetivo.

A personalidade comunicada costuma ser a melhor versão de cada um. Já em 2003, as professoras norte-americanas 


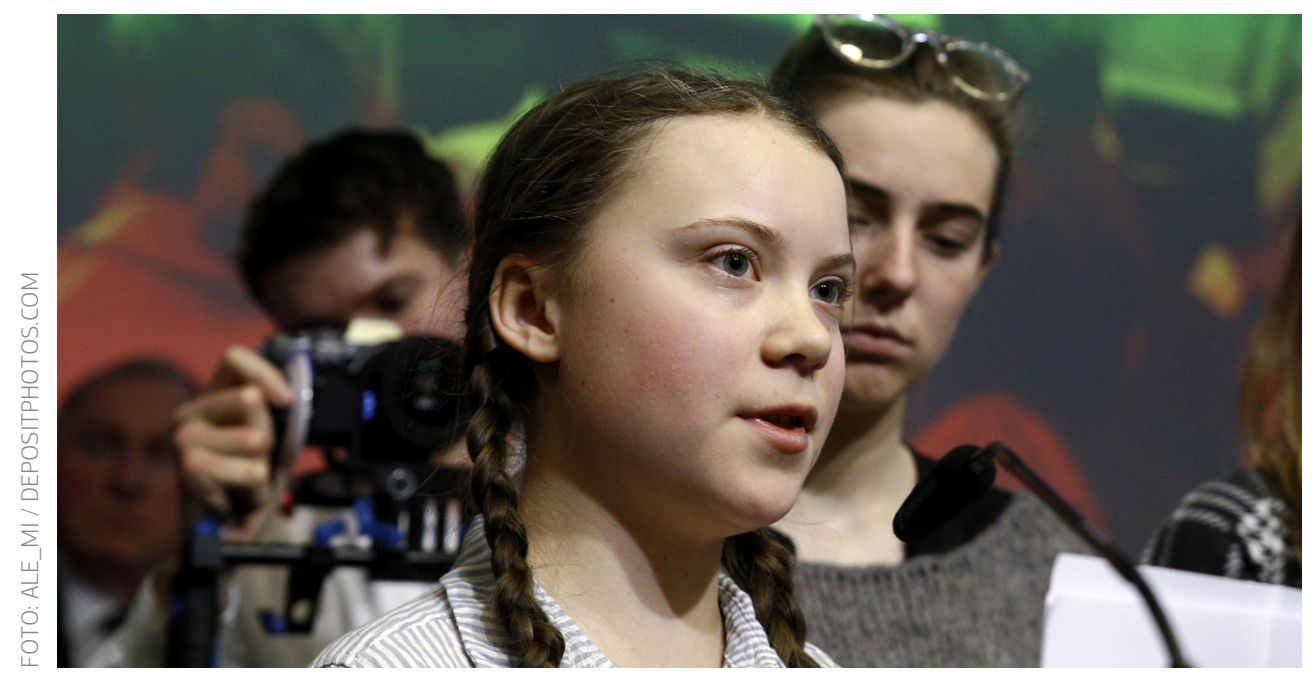

O SELF-BRANDING DA PERSONA DE GRETA THUNBERG

Conteúdo Profissional

(2)

\section{Conteúdo Contextual}

Conteúdo Pessoal

\begin{tabular}{ll}
\hline A ativista busca inspirar as pessoas por meio da causa que defende. Greta faz isso alter- \\
nando estados de humor entre o preocupado e o esperançoso, possivelmente sugerindo \\
a seus seguidores tanto a seriedade do tema quanto a necessidade de usar o otimismo \\
como energia pró-mudança.
\end{tabular}

Conteúdo Instrutivo

Conteúdo Relacional

\section{Elementos Narrativos}

A ativista publica conteúdos sobre as questões climáticas, chamando os agentes relevantes (governos e corporações) à ação, divulgando suas ideias e iniciativas (protestos como o \#schoolstrike4climate, estudos ou reflexões pessoais sobre o tema).

A ativista mostra o que está acontecendo no seu contexto profissional no momento, como suas viagens pelo mundo (frequentemente de barco), os eventos de que participa (como a \#cop25), sua presença na mídia (como na capa da revista Time) e o lançamento de seu livro.

A ativista fala sobre questões pessoais, como seu aniversário, seus cachorros, o natal, mas esse tipo de conteúdo aparece com menor frequência em relação aos demais.

A ativista usa pouco essa possibilidade. Exemplos seriam dicas de como cada um pode agir. A exceção é o pedido constante, direto ou indireto, de que cada um cobre as autoridades e as organizações.

A ativista apresenta ocasionalmente sua relação com demais ativistas, com as pessoas que a acompanham em suas viagens, com os jornalistas que a entrevistam e com personalidades ligadas à questão climática.

A ativista oscila entre o olhar severo diante das questões climáticas e dos eventos e o sorriso diante dos elementos do seu dia a dia, sobretudo na questão pessoal. Curiosamente, essa face é mostrada por ela, mas não tanto pelas demais mídias. A ativista ainda se apresenta visualmente como uma adolescente típica, por exemplo, nas roupas confortáveis e comuns, no cabelo com um simples rabo-de-cavalo, no rosto limpo sem maquiagem e nos lugares que escolhe postar, como gramados, parques e ruas, todos eles muito cotidianos. Algumas fotos saem desfocadas, sugerindo pouca preocupação com elementos de produção. Esses elementos compõem um estilo natural, que tem como efeito levar o público a se sentir próximo dela. 


\section{AS FACES QUE GRETA THUNBERG COMUNICA SÃO AS DE UMA ATIVISTA INCANSÁVEL, DETERMINADA, ENGAJADA E BEM-INTENCIONADA. NẪO DIGO QUE ESSA PERSONA SEJA INTEIRAMENTE VERDADEIRA OU FALSA, MAS PROVAVELMENTE É BASEADA EM ESCOLHAS BEM PENSADAS.}

Hope Jensen Schau e Mary Gilly, ao investigarem sites pessoais, verificaram que o self apresentado na internet para a construção da marca pessoa é um trabalho muito bem curado. Lives, stories, posts, vídeos e artigos são ferramentas de autoexpressão para a promoção de personas planejadas.

O leitor pode questionar: "mas o que é real, autêntico e sincero nisso tudo?". Não vou entrar nesse mérito no artigo, por falta de espaço. Sugiro, no lugar de uma resposta, que cada um observe o mundo com o olhar crítico e atento. As faces que Greta comunica são as de uma ativista incansável, determinada, engajada, bem-intencionada e profundamente incomodada com o mundo à sua volta. Nós não conhecemos a adolescente, apenas a persona produzida para o consumo público. Não digo que seja inteiramente verdadeira ou falsa, mas provavelmente são escolhas bem pensadas.

O tipo de conteúdo na prática de self-branding segue a lógica dos objetivos estabelecidos. De maneira geral, esse conteúdo pode ser de cunho profissional (mostrando quem se é, o que se faz e o que se pensa), pessoal (sobre família, cachorros, amigos, festas), inspirador (que desperta algo positivo por meio da exposição de bons exemplos, pessoais ou de terceiros), instrutivo (sobre o que fazer ou não e como fazer), relacional (revelando quem são os conhecidos) ou contextual (exibindo onde se está e o que se está fazendo em dado momento). O conteúdo também envolve elementos de estilo e narrativa, imagéticos e textuais.

A ativista Greta, por exemplo, mostra conteúdos profissionais e contextuais - divulgando os eventos de ativismo que frequenta, suas viagens de barco, as entrevistas que concede para a grande mídia - e, com menor frequência, conteúdos pessoais ou inspiradores (veja no quadro da página anterior). Em termos de narrativa, ela se apresenta de forma bastante natural, seja nas palavras, seja na expressão corporal ou na forma como se veste. Esse estilo de comunicação sugere aos seguidores estarem em contato com o verdadeiro self de Greta Thunberg, um fenômeno conhecido na psicologia como "relação parassocial", quando se constrói uma impressão de proximidade psicológica entre pessoas que têm um relacionamento distante. Greta consegue com isso aproximar-se das pessoas, o que facilita a promoção da causa climática.

Em muitos casos, ainda há no self-branding uma lógica de conteúdo para o relacionamento potencial com marcas. Nesse caso, além da intenção de comunicar uma persona para o público, o objetivo também é atrair parcerias comerciais, de forma a rentabilizar a marca pessoa.

Há, por fim, decisões sobre o relacionamento com o público que envolvem a preocupação tanto de reforçar ligações com a rede existente quanto de construir laços adequados à estratégia da marca pessoa, seja angariando novos púbicos de interesse, seja via aproximação com outras marcas pessoa adequadas à estratégia. $\mathrm{O}$ aumento da rede segue determinada direção, de acordo com o caminho planejado para a construção da persona.

\section{CONCLUSÃO}

A marca pessoa tornou-se uma prática corrente nas mídias sociais, tanto por parte de pessoas comuns quanto de celebridades. Assim, mais e mais pessoas passarão a enxergar o outro nos meios digitais não como uma pessoa, mas como uma persona. Quais são os efeitos disso sobre a credibilidade e a autenticidade? Creio que exemplos como os de Greta conseguem mostrar a importância de equilibrar a necessidade de comunicar um propósito com a percepção de veracidade.

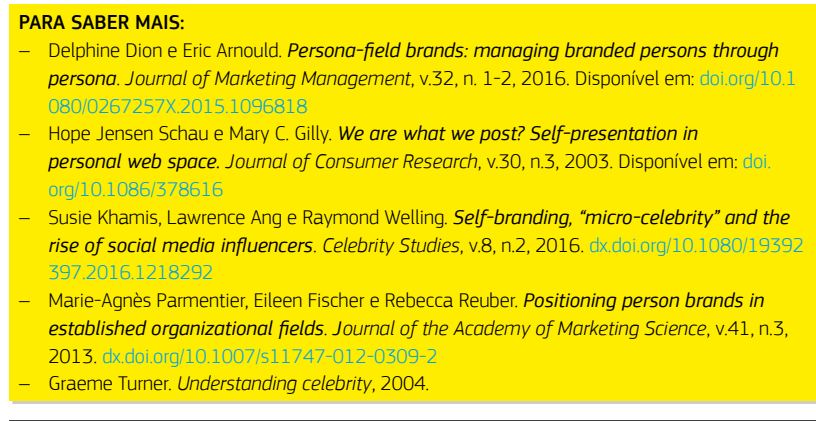

BENJAMIN ROSENTHAL > Professor da FGV EAESP > benjamin.rosenthal@fgv.br 